\title{
Pattern of seminal fluid analysis in a male partner of infertile couple presented in infertility clinic of Patan hospital
}

\author{
Dipti Gautam ${ }^{1}$, Manisha Shrestha ${ }^{1}$, Shiva Raj KC ${ }^{1}$ \\ ${ }^{\prime}$ Department of Pathology, Patan Academy of Health Sciences, Lalitpur, Nepal.
}

\section{Keywords: \\ Azoospermia; Infertility; \\ Oligospermia; \\ Semen analysis;}

\begin{abstract}
Background: Infertility is defined as the failure of a couple to conceive after one year of regular sexual intercourse. The malefactor is responsible for at least $50 \%$ of cases of failure to conceive. Semen analysis remains the cornerstone in the preliminary investigation of male factor infertility. This study aimed to evaluate seminal fluid parameters in the male partners of infertile couples.
\end{abstract}

Materials and Methods: This retrospective study was conducted in the Department of Pathology, Patan Academy of Health Sciences, Patan hospital, Nepal between December 2019 and January 2020. All the 243 specimens were processed and analyzed according to WHO guidelines on semen analysis.

Results: Present study included a total of 243 semen samples, aged between 20-63 years with a mean age of 32.0 years. Normozoospermia was observed in $(26.3 \%)$. The most common abnormalities found in this study were asthenozoospermia (25.5\%), oligospermia (19.3\%), azoospermia (6.5\%), and teratozoospermia.

Conclusion: Semen analysis remains a keystone in assessing male factor infertility in developing countries like Nepal. However, needs further evaluation to establish possible etiologies of male infertility.

\section{Correspondence: \\ Dr. Dipti Gautam, $M D$ \\ Department of Pathology, Patan Academy of Health Sciences, \\ Lalitpur, Nepal \\ ORCID ID: 0000-0003-0887-0775 \\ Email: gdipsy@gmail.com}

Received : July $23^{\text {rd }} 2021$; Accepted : August $28^{\text {th }} 2021$

Citation: Gautam D, Shrestha M, KC Shiva R. Pattern of seminal fluid analysis in a male partner of infertile couple presented in infertility clinic of Patan Hospital. 2021;11(2):2021:11(2): 1813-6. DOI: 10.3126/jpn.v11i2.41391

Copyright: This is an open-access article distributed under the terms of the Creative Commons Attribution 4.0 International License, which permits unrestricted use, distribution, and reproduction in any medium, provided the original author and source are credited.

\section{INTRODUCTION}

According to the International Committee for Monitoring Assisted Reproductive Technology, World Health Organization (WHO), infertility is a disease of the reproductive system defined by the failure to achieve a clinical pregnancy after 12 months or more of regular unprotected sexual intercourse. ${ }^{1}$ Infertility is a major clinical and public problem affecting the life of the couple. Infertility remains a very sensitive issue worldwide and social stigma persists in Nepal. The average prevalence of infertility in developed countries is $3.5-16.7 \%$ and in developing countries is 6.9 $9.3 \% .^{2}$ Of all infertility cases, about $40-50 \%$ is due to infertility of the male component. ${ }^{3}$ Semen analysis plays a 
critical role in the assessment of male factor infertility and usually forms part of the initial investigation undertaken by an infertile couple. ${ }^{4}$ World Health Organization (WHO) had defined normal values for semen analysis, which includes complete liquefaction within 60 minutes at room temperature, homogenous, gray, and opalescent appearance. A good sperm consistency is demonstrated by semen living the pipette as discrete droplets, semen volume greater or equal to $2 \mathrm{ml}$, and a $\mathrm{pH}$ greater or equal to 7.2. Other normal parameters include a concentration of greater or equal to 20 million sperm cells per $\mathrm{ml}$, motility of $50 \%$ or more with forwarding progression, and a morphology of $30 \%$ or more normal forms. ${ }^{5}$ This study aimed to evaluate seminal fluid parameters in the male partners of the infertile couples presenting to the infertility clinic of Patan Hospital.

\section{MATERIALS AND METHODS}

All the patients who attended the infertility clinic of Patan hospital and whose semen were sent to the laboratory for analysis. This retrospective study was conducted in the Department of Pathology, Patan Academy of Health Sciences between December 2019 and January 2020. Data were extracted from the Medical Record sections and hospital information management system. Permission was obtained from the institutional review committee to conduct the study. The variables considered in the study are patient demographic data, clinical diagnosis, and relevant microscopic findings of semen. The data was uploaded and analyzed using Microsoft Excel and SPSS version 23.0. Normally distributed data are expressed as mean \pm standard deviation (SD).

The samples were obtained from the patients who had 3 days of abstinence from sexual intercourse. All the samples were incubated at $370 \mathrm{C}$ and analyzed within one hour of collection by manual method. Based on WHO guidelines ( 5 th edition) of standard procedure, semen analysis was carried out by determining initial macroscopic examination (semen liquefaction, viscosity, appearance, volume, and $\mathrm{pH}$ ); the wet preparation was made to determine the concentration sperm motility, sperm vitality, sperm numbers, concentration, motility, morphology, viability, and the presence of WBC or RBC. Motility of the sperm is graded as follows: Forward progressive motility (PR), nonprogressive motility (NP), and immotile (IM). Sperm vitality was determined by mixing one drop of eosin solution with one drop fresh sample and was examined at 400x under the microscope. The test is based on the principle that dead cells with damaged plasma membranes take stains.

\section{RESULTS}

During the study period, 243 males visited the infertility clinic. The mean age in this study was 32.0 years with the maximum being 63 years and the minimum being 20 years. Most of the patients were between the age group of
Table 1: Distribution of cases on basis of semen defects

\begin{tabular}{lcc}
\hline Semen pattern & No. of cases & \% \\
\hline Normozoospermia & 64 & 26.3 \\
\hline Oligospermia & 47 & 19.3 \\
\hline Vitality $(<\mathbf{5 8 \% )}$ & 50 & 20.5 \\
\hline Azoospermia & 16 & 6.5 \\
\hline Asthenozoospermia & 62 & 25.5 \\
\hline Teratozoospermia & 2 & 0.8 \\
\hline Oligoasthenoteratozoospermia & 2 & 0.8 \\
\hline Total & 243 & 100 \\
\hline
\end{tabular}

20-35 years $(n=184 ; 75.5 \%)$. Among the study population, the mean semen volume, sperm concentration, progressive motility, and vitality of the semen were $2.87 \mathrm{ml}, 49.6$ million $/ \mathrm{ml}$, and $34.7 \%$ respectively (Table 1 ). Semen volume was decreased in 21 males (7.4\%). Using WHO standard for semen normality, 243 samples were analyzed, out of these 243 (26.3\%) had normozoospermic. An abnormal seminogram was seen in $161(66.2 \%)$. According to agewise distribution maximum cases of oligospermia $(15.6 \%)$ were between the age group of 20-35 years (Table 2).

Single-factor abnormalities were observed in $216(88.8 \%)$ cases and 27 (11.1\%) had combined factor abnormalities. Oligoasthenozoospermia was observed in 13(5.3\%) cases, which is highest among the combined abnormalities followed by oligospermia with vitality $<58 \%$ in $12(4.9 \%)$ cases. Asthenozoospermia was the main single abnormality found followed by vitality $<58 \%$. Azoospermia was detected in $16(6.5 \%)$ cases with the highest incidence between 20 35 years (Table 3$)$. Haemospermia was found in $7(2.8 \%)$ cases.

\section{DISCUSSION}

Globally, the male is considered to be a factor in nearly onethird of couples affected by infertility. It has just recently been recognized as a substantial cause of infertility. ${ }^{6}$ Male infertility is not a single entity, but rather the result of a multitude of pathogenetic pathways. ${ }^{7}$

Semen analysis is one of the basic investigations in the process of identifying the cause of primary or secondary infertility. The present study was conducted to evaluate seminal fluid parameters in our population and to find out the frequency and type of abnormal semen parameters. Commonly, patients visit the fertility clinic after not being able to conceive within a few years of marriage. In our context, the high age for family planning is in the mid-20s and 30s. In concordance with this social norm, $75.5 \%$ of our patients comprised of 20-35 years age-group with a mean age of 32 years. This coincides with other studies done in this region with similar social norms. ${ }^{10}$ The present study expressed more than two-thirds of the male partner had 
Table2: Age-wise distribution of semen volume, concentration, and vitality among the study population (n=243)

\begin{tabular}{lccccccc}
\hline Age & Vol. $<\mathbf{1 . 5 m l}$ & Vol. $\geq \mathbf{1 . 5 m l}$ & Conc. $<\mathbf{1 5} \mathbf{~ m l}$ & Conc. $\geq \mathbf{1 5} \mathbf{~ m l}$ & Vitality $<\mathbf{5 8 \%}$ & Vitaliy $>\mathbf{5 8 \%}$ \\
\hline $\mathbf{2 0 - 3 5}$ & 18 & 170 & 38 & 146 & 29 & 154 \\
$\mathbf{3 6 - 5 0}$ & 3 & 50 & 7 & 0 & 20 & 8 & 45 \\
\hline $\mathbf{5 1 - 6 5}$ & 0 & 2 & $\mathbf{2 2 2}(\mathbf{9 1 . 3} \%)$ & $\mathbf{4 5}(\mathbf{1 8 . 5} \%)$ & $\mathbf{1 9 8}(\mathbf{8 1 . 4} \%)$ & $\mathbf{5 4 ( 2 2 . 2 \% )}$ & $\mathbf{1 8 9 ( 7 7 . 7 \% )}$ \\
\hline Total & $\mathbf{2 1}(\mathbf{8 . 6} \%)$ &
\end{tabular}

Vol.- Volume; Conc.- Concentration

Table 3: Age-wise distribution of semen parameters

\begin{tabular}{lccccc}
\hline Age & Oligospermia & Teratozoospermia & Azoospermia & Asthenozoospermia & Oligoasthenoteratozoospermia \\
\hline $\mathbf{2 0 - 3 5}$ & 21 & 2 & 14 & 20 & 1 \\
$\mathbf{3 6 - 5 0}$ & 3 & 0 & 2 & 4 & 1 \\
\hline $\mathbf{5 1 - 6 5}$ & 0 & 0 & 0 & 1 & 0 \\
\hline Total & $\mathbf{2 4}(\mathbf{9 . 8} \%)$ & $\mathbf{2 ( 0 . 8 \% )}$ & $\mathbf{1 6}(6.5 \%)$ & $\mathbf{2 5}(\mathbf{1 0 . 2} \%)$ & $\mathbf{2 ( 0 . 8 \% )}$ \\
\hline
\end{tabular}

abnormal seminogram.

Semen volume less than $1.5 \mathrm{ml}$ was observed in $8.6 \%$ of cases. This is similar to the study done by Bhaduri $\mathrm{N}$ et al ${ }^{11}$ (7.45\%) and Prashant Joshi et $\mathrm{al}^{9}(6 \%)$. Low semen volume results from the ejaculatory duct obstruction or congenital bilateral vas deferens absence, as well as collection problems, incomplete retrograde ejaculation, and androgen deficit. Among the 243 cases, the present study had found normal vitality in more than two-thirds of the cases.

Sperm concentrations are often proposed to be predictors of fertility potential ${ }^{12}$. In recent years there have been reports of declining sperm concentration in men around the world $^{13}$. In this study, cases of oligospermia were found in $19.3 \%$ of cases. Similar findings were reported by Bhaduri et $\mathrm{al}^{11}$ and KalakondaM et al. ${ }^{12}$ While the study conducted by Kumar et al $(34 \%)^{13}$, is in contrast to the present study. This high percentage might be due to the large sample size. According to the authors, low sperm counts are one of the most common causes of male infertility. ${ }^{14,15}$ Association of oligospermia with increased morphological abnormalities has been suggested by Butt et.al. ${ }^{16}$

Poor motility (Asthenozoospermia) was the single factor common abnormality found in this study constituting $25.5 \%$ which was in concordance with the study was conducted by Garg $\mathrm{J}$ et $\mathrm{al}^{17}$, Bodal et $\mathrm{al}^{18}$, Ugbaoja et $\mathrm{al}^{19}$ and that reported the prevalence of asthenozoospermia 14.3\%,17\%, and $16.5 \%$ respectively. However, a low percentage of asthenozoospermia was found in a study conducted by Aulia et al $(5.9 \%)^{20}$ and Diallo et al $\left.(10 \%)\right)^{21}$ The total number of progressively motile spermatozoa in the ejaculate is of biological significance. ${ }^{14,15}$ However, the motility of the spermatozoa could be affected by environmental factors, lifestyle, and pollution which explains these differences.

Among the subject in this study, azoospermia was recorded in $6.5 \%$ of subjects. This study was similar to the study conducted by Jairajpuri et al $(8.6 \%){ }^{22}$ This was lower than previous studies' findings conducted by Butt $\mathrm{F}$ et al $(14.8 \%)^{16}$, Emma-Okon et al. $(12.3 \%)^{23}$, and Bakhtawar Gul
Wazir et al (28.6\%). ${ }^{24} \mathrm{~A}$ difficulty with sperm production or transport is assumed to be the cause of azoospermia.

Morphology of the sperm is the function of the testes as well as the epididymis. Teratozoospermia and Oligoasthenoteratozoospermia were found in $0.8 \%$ of cases each. Butt and Akram reported it 9.09\%. ${ }^{16}$ Aulia et al. reported $11.6 \%$ cases 20 and Kulkarni et al $7.3 \% 25$ of cases. Teratozoospermia has a negative impact on fertilization rates. ${ }^{26}$ Idiopathic factors also contribute to infertility. A study in Poland trying to investigate the pattern of infertility reported that $16 \%$ of male infertility was due to idiopathic causes. ${ }^{26}$

The presence of pus cells in the male genital tract, red blood cells, as well as agglutination of the sperms, are all morbidity factors. It may have an impact on seminal quality by acting directly on spermatozoa or their surroundings.

The present study only illustrates an abnormal pattern of seminal fluid analysis of malefactors. The presumptive causative factors/risk factors account for these aberrant semen patterns, which were not discussed in this study, also the types of infertility were not explained. As a result, further research is needed to understand the causes of male factor infertility, which will eventually aid in the management of male infertility situations.

\section{CONCLUSIONS}

Routine semen analysis is still the gold standard for assessing male factor infertility in developing countries like Nepal, but it is vital to recognize its limitations in terms of collection, processing, and interpretation, as well as biological variance in the parameters and a lack of information on sperm activity. In the present study asthenospermia is the most common abnormality followed by oligospermia. Our findings suggest that poor sperm quality continues to play a significant role in overall infertility in our environment and that men are coming to terms with the fact that they may potentially be a contributing factor. The causal issues must be identified, and artificial insemination should be promoted 
in cases when therapeutic recovery is not possible.

Acknowledgments: We are thankful to all the members of the Department of Pathology for their great help throughout this work.

\section{Conflict of interest: None}

\section{REFERENCES}

1. Zegers-Hochschild F, Adamson GD, Mouzon J. de et al. International Committee for Monitoring Assisted Reproductive Technology (ICMART) and World Health Organization (WHO) revised glossary of ART Terminology, 2009. Fertilsteril, 2009;92:1520-4. Crossref

2. Boivin J, Bunting L, Collins J, Nygren K. International estimates of infertility prevalence and treatment-seeking: potential need and demand for infertility medical care. Hum Reprod. 2007;22: 1506-12. $\underline{\text { Crossref }}$

3. Winters BR, Walsh TJ. The epidemiology of male infertility. Urol Clin North Am 2014; 41(1):195-204. Crossref

4. Silverberg KM, Turner T. Evaluation of Sperm. In: Gardner DK, Weissman A., Howles C.M. and Shoham Z, editors. Textbook of assisted reproductive techniques. 2 nd edition. London: Taylor and Francis; 2004. p. 65-78.

5. WHO laboratory manual for the examination and processing of human semen. 5th ed. WHO Press, World Health Organization, 20 Avenue Appia, 1211 Geneva 27, Switzerland; 2010. p. 7-113.

6. Seibel MM. Workup of the infertile couple. In: Seibel MM. (ed.) Infertility A Comprehensive Text-global Book. Appleton and Lange, Connecticut. USA: Norwalk; 1990. p. 1-21.

7. Shakkeback VE, Giwercman A, de-krester D, Pathogenesis and management of male infertility. Lancet 1994;343(11):1473-9. $\underline{\text { Crossref }}$

8. Juneja P, Phukan PK, Changmai D. A study of abnormal semen parameters in infertile couples in Assam, India. Project: Serum AMH to predict ovarian reserve. Int J Reprod Contracept Obstet Gynecol :7:997-1000. Crossref

9. Joshi P, N Gopal, Bhat V. Study of semen analysis pattern in infertile males. International Journal of Pharmacy and Biological Sciences 2011;1: 44-9. Crossref

10. Ramaya C, Renuka IV, Premathala P, Mahadevi K. Pattern of semen analysis in male parteners of infertile couples at tertiary centre in Karnatak, India. Indian Journal of Pathology and Oncology 2017;4(4):536-9 Website

11. Bhattacharya N, Sarkar AS, Dewasi N, Ghosh TK. Abnormalities in semen analysis among male partners of infertile couples: a study in a tertiary care level hospital of West Bengal. Int J Reprod Contracept Obstet Gynecol. 2015;4(1):100-2. Website

12. Kambala GM, Kalakonda M, Undavalli VK, Pattern of Semen Analysis: An Insight into Male Infertility at a Tertiary Care Hospital. IOSR Journal of Dental and Medical Sciences 2018; Issue: PP 30-3. $\underline{\text { Website }}$

13. Kumar N, Singh AK. Trends of male factor infertility, an important cause of infertility: A review of literature. J Hum Reprod Sci. 2015; 8(4): 191-6. Crossref

14. Khan MS, Deepa F, Ahmed Z, Tahir F, Khan MA. Assessment of male reproductive health by conventional method of semen analysis. J Ayub Med Coll Abbottabad. 2011;23:84-8. Website

15. Opoku A, Boateng D,Quansah DY, Bedu-Addo K, Ankobea-Krokoe F. Semen Characteristics of Male Infertile Couples in the Kumasi Metropolis: A Study of Primary and Secondary Infertile Couples. Br Journal of Med \& Med Res. 2014;4(6):1432-41. Crossref

16. Butt F, Akram N. Semen analysis parameters: experiences and insight into male infertility at a tertiary care hospital in Punjab. J Pak Med Assoc. 2013;63(5):558-62. Website
17. Garg J, Meena R, Shukla S, Abnormal semen parameters among males in infertile couples: a cross sectional study from a tertiary care centre. Int J Reprod Contracept Obstet Gynecol. 2020;9(8):3398401. Crossref

18. Bodal VK, Malik R, Kaur S, at el. Seminogram in male partners of infertile couples. International Journal of Medical and Dental Sciences 2014; 3(1):276-84. $\underline{\text { Crossref }}$

19. Ugwa EA, Ashimi A, Abubakar MD, Obadire S. Poor semen parameters among infertile couples presenting at a gynaecological clinic of Federal Medical Centre Birnin Kudu North-west Nigeria. Nigerian Medical Journal 2015; 56: 283-6. $\underline{\text { Crossref }}$

20. Aulia SN, Lestari SW, Pratima G. The pattern of abnormalities on sperm analysis: A study of 1186 infertile male in Yasmin IVF clinic Jakarta, J. Phys.: Conf. Ser. 2017; 884 012138. Crossref

21. Diallo MS, Diallo SA, Fosto P, Diallo Y, Diao B, Faye O. Semen abnormality patterns and parameters in male partners of infertile couples in dakar (Senegal). Open Journal of Urology, 2015; 5:15560. $\underline{\text { Crossref }}$

22. Jairajpuri, Z. S., Rana, S., Ali, M. A., Pujani, M., \& Jetley, S. Pattern of semen analysis: Experiences of a labrotorary catering to semi urban population of Delhi. Bangladesh Journal of Medical Science 2017; 6(2), 314-9. Crossref

23. Emma-Okon BO, Fasubaa OB, Togun RA, Fakunle JB, Awoniyi A, Adediran T. Semen Profile in Ile-Ife, Nigeria in Relation to New WHO Guidelines. Journal of Medicine and Medical Science 2011; 2(5): 879-84. Website

24. Wazir BG, Orakzai AN, Ikramullah, Nawaz A, Rafiq N. Male Factor Infertility: Five Years Experience. Ann Pak Inst Med Sci 2010; 6(1): 7-10. Website

25. Kulkarni SN, Kulkarni NV. Study of semen parameters in male partners among infertile couples. Int J Reprod Contracept Obstet Gynecol. 2015;4(4):1016-9. Crossref

26. Mendoza JC, Cubillos J, Ortiz G, Arango A, Diaz M, Ruiz H. Isreliable the new semen analysis of the WHO laboratory manual for the diagnosis of the male factor in an infertile population? JBRA Assist Reprod.2013;17(2):98-100. Crossref 